\title{
Acceptability of Telemedicine Features to Promote Its Uptake in Practice: A Survey of Community Telemental Health Providers
}

\author{
Brian E. Bunnell ${ }^{1,2, *}$, Janelle F. Barrera ${ }^{1,2}$, Samantha R. Paige ${ }^{2}$, Dylan Turner ${ }^{2}$ \\ and Brandon M. Welch ${ }^{2,3}$ \\ 1 Department of Psychiatry and Behavioral Neurosciences, Morsani College of Medicine, \\ University of South Florida, Tampa, FL 33612, USA; jfb@usf.edu \\ 2 Doxy.me, LLC, Rochester, NY 14623, USA; samantha.paige@doxy.me (S.R.P.); dylan@doxy.me (D.T.); \\ brandon@doxy.me (B.M.W.) \\ 3 Biomedical Informatics Center, College of Medicine, Medical University of South Carolina, \\ Charleston, SC 29403, USA \\ * Correspondence: bbunnell@usf.edu; Tel.: +(813)-794-8607
}

Received: 27 September 2020; Accepted: 13 November 2020; Published: 17 November 2020

\begin{abstract}
Understanding what motivates mental health providers to use telemedicine (i.e., telemental health) is critical for optimizing its uptake, especially during unprecedented times (e.g., the COVID-19 pandemic). Drawing from the Technology Acceptance Model (TAM), this report examined the characteristics of telemental health providers and how the acceptability of telemedicine features contributes to their intention to use the technology more often in practice. Telemental health providers $(N=177)$ completed an online survey between March and May 2019. Most providers $(75 \%)$ spent less than $25 \%$ of their work-week using telemedicine, but $70 \%$ reported an intention to use telemedicine more in the future. The belief that telemedicine affords greater access to patients, work-life balance, flexibility in providing care, and the opportunity to be at the forefront of innovative care were significant predictors of intentions to use the technology more in the future. Other significant predictors included needing assistance to coordinate insurance reimbursements, manage a successful telemedicine practice, and integrate the telemedicine program with other health IT software. Findings have important implications for increasing the frequency of telemedicine use among telemental health providers. Future research and practice should leverage providers' positive beliefs about telemedicine acceptability and consider their needs to enhance its uptake.
\end{abstract}

Keywords: telehealth; telemedicine; mobile health; mental health; technology acceptance

\section{Introduction}

Widespread Internet access and advancements in technology have revolutionized how healthcare is delivered to prevent and manage the leading causes of death and disability worldwide. Mobile health (mHealth) technologies, for example, support non-clinical care delivery (e.g., health education and data reporting and monitoring) as well as clinical intervention between patients and providers [1]. This clinical application, termed telemedicine, leverages information communication technology to enable providers to remotely deliver healthcare services and consultations to patients through video conferencing, among other modalities [2]. Alongside growing evidence for its clinical and cost-effectiveness, telemedicine has changed the way that healthcare is practiced in unprecedented times, such as the COVID-19 pandemic [3,4].

Telemedicine supports the provision of healthcare for a variety of conditions (e.g., diabetes, hypertension, heart failure, cancer) [5-9], but its potential to shape the delivery of mental health 
care is undeniable. Systematic and meta-analytic reviews have demonstrated that mental health treatment delivered via telemedicine, or telemental health, is equally, and in some cases more, effective than treatment delivered in-person and results in higher patient satisfaction at reduced costs [10-13]. The effectiveness and satisfaction of telemental health treatment is likely to be due to its ability to alleviate physical (e.g., travel time, missed work, and financial costs) and socio-cultural (e.g., concerns relating to stigma) barriers that are notorious for impeding healthcare accessibility and continuity [14-18].

In a review of Medicare fee-for-service claims between 2014 and 2016, psychiatrist telemental health providers were more likely to be early in their careers, employed in large practices, and serving rural regions as compared with psychiatrists who did not use telemental health services [19]. Despite this knowledge, little is known about the characteristics of community telemental health providers, including their use of telemedicine and the factors that motivate them to use the technology [20-22]. To date, only two studies have surveyed mental health providers about their use and perceptions of telemedicine. Simms et al. [23] surveyed Canadian mental health providers, half of whom had been practicing for 10-20+ years. This survey found that only $40 \%$ had provided telemental health (i.e., video conferencing) to their patients and that these services were provided about once per year, on average. Of those providers, $75 \%$ did not receive training in how to provide telemental health services. Having been practicing for longer, previously receiving telemental health training, and perceiving the technology to be easy-to-use were also associated with more frequent telemedicine use. In another study, Gershkovich et al. [24] surveyed a sample of mental health providers recruited through listservs and mailing lists of state, national, and international behavioral health organizations. Approximately $72 \%$ of the providers used remote patient services (i.e., telephone, email, videoconferencing, instant messaging, and free-standing websites). However, only $\sim 27 \%$ had used videoconferencing (i.e., $16 \%$ of the entire sample), with less than $10 \%$ reporting regular use. Despite this promising evidence, the diffusion and uptake of telemental health care in community mental health clinics has lagged [25-27]. There is a need to understand the trends in telemental health use, as well as the characteristics of mental health providers who embrace its use in practice. This includes providers other than psychiatrists, including mental health counselors and social workers.

Mental health providers are "gatekeepers" to the implementation of telemedicine in every-day clinical practice [27-29]. A commonly cited factor that hinders the uptake of telemental health visits includes slow-shifting public policies that leave concerns about being reimbursed by health insurance companies [25]. This is likely to be why less than $20 \%$ of telemental health providers eventually bill insurance companies for providing the service [24]. Given the potential of telemedicine to alleviate disparities in accessing community mental health treatment, empirical evidence is needed to describe factors that contribute to telemental health providers' acceptability and the ultimate uptake of their telemedicine platform in clinical practice.

Drawing from the tenets of the Technology Acceptance Model (TAM), an individual's intention to use a technology is driven by its perceived acceptability, which is broadly conceptualized according to the user's beliefs about its usefulness and ease-of-use [30]. A recent systematic review found that the TAM is the most widely used model to guide technology acceptance research in telemedicine, which is due to its simplicity and capacity to explain the high amount of variance in data $\left(M d n R^{2}=0.68\right)$ [31]. Results of the review further demonstrated that the perceived usefulness of telemedicine has the strongest predictive power in telemedicine uptake intentions among healthcare providers. For healthcare providers, the perceived usefulness of telemedicine is dependent on intentions about its efficiency to streamline diagnosis, disease monitoring, and treatment [31].

In prior research, about $50 \%$ of mental health providers rate telemental health visits as very/somewhat useful and 34\% rated it to be somewhat easy/very easy to use [23]. According to Gershkovich et al. [24], commonly endorsed beliefs that reinforce the use of telemental health services include the ability to reach clients from a distance, convenience for clients and therapists, real-time monitoring and intervention, increased access to specialized care, and low-cost services. 
On the other hand, common challenges that disengage positive beliefs about telemedicine include limited personal connections due to mediated contexts, addressing technological difficulties, uncertainty about legal issues, privacy concerns, and challenges responding to crisis situations. As such, the acceptability of telemental health includes positive and negative beliefs about its features. There is a significant need to understand user acceptance according to the features that motivate its initial use and features that need improvement to secure long-term use by providers. This evidence will inform more precise intervention to support provider acceptance, uptake, and sustained use of telemedicine over time.

The purpose of this report is to describe the characteristics of community telemental health providers, with strong attention paid to better understanding which telemedicine features characterize its acceptance and frequent use in the future. A secondary aim is to provide a pre-COVID-19 pandemic baseline assessment for various aspects of the acceptability of these features. Telemedicine was quickly identified as a healthcare delivery solution, while risk mitigation guidelines were implemented [3,32]. With statements suggesting that telemedicine will remain an integral aspect of healthcare delivery post-COVID-19 [33], it becomes valuable to document baseline data for monitoring trends regarding the beliefs about telemedicine features in this profession. Findings of this report have important practical and theoretical implications for increasing the frequency of telemedicine uptake in clinical practice.

\section{Materials and Methods}

\subsection{Sample and Procedures}

This is a retrospective review of cross-sectional, de-identified data from a 15-min web-based marketing survey administered among practicing community telemental health providers registered with doxy.me (https://doxy.me/), a HIPAA-compliant telemedicine solution with more than 700,000 active provider users. Between 25 March 2019 and 1 May 2019, providers who indicated mental/behavioral health as their clinical specialty under their doxy.me profile received an email invitation to complete the survey. Of the 1944 providers who were sent email invitations, $290(14.9 \%)$ started the survey and 177 (9.1\%) completed it. Prior to the survey, providers were directed to an electronic consent form where they indicated their agreement to have their de-identified data used for marketing research and publication. Compensation was not offered, and the Institutional Review Board at the University of South Florida determined that use of this data for publication does not constitute research involving human subjects.

\subsection{Measures}

The survey was developed through an iterative process with marketing and leadership teams based on their knowledge and experience of telemedicine, consultation with a licensed clinical psychologist with telemedicine experience (i.e., the first author), and prior relevant survey studies [34,35]. It was also reviewed for readability, relevance to the mission of the company, and efficiency of completion. Survey items included demographic (e.g., gender, race, ethnicity) and professional questions (e.g., highest level of education achieved, mental health specialty and setting, the proportion of time spent providing telemental health services, health insurance billing practices, reason for integrating telemedicine into their current practice). Next, providers were asked to indicate which features of telemedicine serve as benefits (e.g., can see patients wherever they are, can have a better work-life balance) and barriers (e.g., security/privacy concerns, reimbursement issues) to their practice. The selection of each benefit and barrier was measured dichotomously, where $1=$ yes and $0=$ no. Next, providers were asked to select the reasons for using their current telemedicine platform, the telemedicine features that are most important to their practice, and the telemedicine features that need to be improved. For each of the aforementioned variables, providers were presented with a predetermined list of telemedicine features (e.g., HIPAA compliance, low cost, no downloads) and asked to select all that apply, where $1=$ yes and $0=$ no. Finally, providers were asked about their 
intention to use telemedicine in the future with three response options (i.e., I expect to use it "less often, the same, or more"). Only $n=1$ selected "I expect to use it less often." As a dependent variable for our logistic regression model, this participant was excluded and the variable was reduced to "I expect to use it about the same" $=0$ and "I expect to use it more" $=1$.

\subsection{Data Analysis}

We used SPSS Version 27.0 (Armonk, NY: IBM Corp.) to describe the demographic and professional characteristics of the sample. To address the aims of the report, we also computed descriptive statistics to examine variables intended to describe telemedicine acceptability (i.e., features that are benefits or barriers of telemedicine, features contributing to the decision to use telemedicine, telemedicine features that are important, and telemedicine features that could be improved) and intentions for using telemedicine more often in the future. We conducted five multiple logistic regression analyses to examine the association between intentions to use telemedicine in the future $(0=$ the same amount; 1 = more often) and: (1) benefits of using telemedicine; (2) barriers of using telemedicine; (3) reasons for using current telemedicine platform; (4) important telemedicine features; and (5) telemedicine features that need improvement. Each regression analysis was a single-step model. Tolerance and variation inflation factors (VIF) were consisted to ensure that multi-collinearity was not a threat to model interpretation. There was a statistically non-significant $(p>0.05)$ association between demographic factors and intentions to use telemedicine more often in the future; therefore, the models did not include these variables as covariates.

\section{Results}

\subsection{Telemental Health Provider Characteristics}

Table 1 shows provider demographics. Community telemental health providers were, on average, 46.4 years old $(S D=12.2$ years; $\min =26$ and $\max =83)$. The majority of providers identified as female $(68.9 \%)$, white $(78 \%)$ and non-Hispanic (90.4\%). Providers had been providing mental health care for an average of 13.6 years $(S D=10.4 ; \min =1$ and $\max =49$ years $)$ and had been telemental health providers for an average of 2.1 years $(S D=1.9$; $\min =<1$ and $\max =10)$. Roughly two-thirds had obtained a master's degree (63.8\%) and $25.4 \%$ had received a doctoral degree (i.e., PhD or PsyD).

Most of the telemental health providers were employed by individual practices $(69.5 \%)$ or small clinics (18.1\%). Among providers who were employed by individual practices, most were mental health counselors $(n=37 ; 30.1 \%)$, psychologists $(n=32 ; 26 \%)$ or social workers $(n=27 ; 22 \%)$, whereas less than $4 \%$ were primary care providers, psychiatrists, or health coaches. A similar trend existed for small clinics, with the majority of providers being mental health counselors $(n=14 ; 43.8 \%)$, psychologists $(n=5 ; 15.6 \%)$, or social workers $(n=6 ; 18.8 \%)$.

\subsection{Characteristics of Telemedicine Use in Clinical Practice}

Table 2 demonstrates that nearly $85 \%$ of providers spent over a quarter of their work-week providing mental health care to patients; only about $25 \%$ spent over a quarter of this time providing telemental health care. A combination of in-person and telemedicine sessions (44.1\%) or only using telemedicine when necessary $(46.9 \%)$ were reported by providers. Only half $(50.6 \%)$ of the providers reported billing health insurance companies for telemental health visits. Not shown in Table 2, providers who billed insurance companies were mental health counselors $(38.9 \%)$, social workers $(24.4 \%)$, and clinical psychologists in independent practices $(69.5 \%)$ and clinics $(18.1 \%)$. 
Table 1. Characteristics of telemental health providers, $N=177$.

\begin{tabular}{|c|c|}
\hline Demographic Characteristics & $M(S D)$ or $n(\%)$ \\
\hline Age, $M(S D)$ & $46.4(12.2)$ \\
\hline \multicolumn{2}{|l|}{ Sex, $n(\%)$} \\
\hline Female & $122(68.9)$ \\
\hline Male & $55(31.1)$ \\
\hline \multicolumn{2}{|l|}{ Race, $n(\%)$} \\
\hline White & $138(78.0)$ \\
\hline More than one race & $13(7.3)$ \\
\hline Black or African American & $13(7.3)$ \\
\hline Asian & $11(6.2)$ \\
\hline American Indian/Alaska Native & $1(0.6)$ \\
\hline Unknown & $1(0.6)$ \\
\hline \multicolumn{2}{|l|}{ Ethnicity, $n(\%)$} \\
\hline Hispanic & $15(8.5)$ \\
\hline Not Hispanic/Latino & $160(90.4)$ \\
\hline \multicolumn{2}{|l|}{ Highest education level, $n(\%)$} \\
\hline Master's degree & $113(63.8)$ \\
\hline Doctor of Philosophy (PhD) & $27(15.3)$ \\
\hline Doctor of Psychology (PsyD) & $18(10.1)$ \\
\hline Medical Doctor/Doctor of Osteopathic Medicine (MD/DO) & $12(6.7)$ \\
\hline Bachelor's degree & $3(1.7)$ \\
\hline Doctor of Nursing Practice (DNP) & $2(1.1)$ \\
\hline Doctor of Pharmacy (PharmD) & $1(0.6)$ \\
\hline Other & $2(1.1)$ \\
\hline Professional Characteristics & $M(S D)$ or $n(\%)$ \\
\hline Years providing mental health care, $M(S D)$ & $13.6(10.4)$ \\
\hline Years providing telemental health care, $M(S D)$ & $2.1(1.9)$ \\
\hline \multicolumn{2}{|l|}{ Provider specialty, $n(\%)$} \\
\hline Mental health counselor (LMHC, LPC) & $58(32.8)$ \\
\hline Psychologist (PhD, PsyD) & $39(22.0)$ \\
\hline Social worker (LCSW) & $37(20.9)$ \\
\hline Clinical provider (Other) & $21(11.9)$ \\
\hline Primary care provider (MD, NP, Physician Assistant or PA) & $9(5.1)$ \\
\hline Psychiatrist (MD) & $5(2.8)$ \\
\hline Non-clinical professionals (e.g., health coach) & $3(1.7)$ \\
\hline Specialty physician & $4(2.3)$ \\
\hline Therapy/rehabilitation provider & $1(0.6)$ \\
\hline \multicolumn{2}{|l|}{ Type of practice, $n(\%)$} \\
\hline Individual practice & $123(69.5)$ \\
\hline Part of a small clinic & $32(18.1)$ \\
\hline Part of a network of providers & $13(7.3)$ \\
\hline College or university & $2(1.1)$ \\
\hline Hospital or large health organization & $2(1.1)$ \\
\hline Primary/secondary school (Kindergarten - Grade 12) & $1(0.6)$ \\
\hline Other & $4(2.3)$ \\
\hline
\end{tabular}


Table 2. Telemedicine use among mental health providers, $N=177$.

\begin{tabular}{ccc}
\hline Characteristics of Telemedicine Use & $n$ & $\%$ \\
\hline Percentage of work week spent providing care to patients & 26 & 14.7 \\
$<25 \%$ & 28 & 15.8 \\
$25-50 \%$ & 47 & 26.6 \\
$50-75 \%$ & 75 & 42.4 \\
$>75 \%$ & 1 & 0.6 \\
Missing & 132 & 74.6 \\
$<25 \%$ & 19 & 10.7 \\
$25-50 \%$ & 12 & 6.8 \\
$50-75 \%$ & 14 & 7.9 \\
$>75 \%$ & 83 & 46.9 \\
Percentage of time providing care to patients via telemedicine & 78 & 44.1 \\
Patterns of telemedicine use & 16 & 9.0 \\
Use telemedicine only when necessary & & \\
Use telemedicine for all appointments & 90 & 50.6 \\
Billing insurance for telemedicine visits & Bill insurance &
\end{tabular}

\subsection{Perspectives on Telemedicine Use in Mental Health Care: Perceived Benefits and Barriers}

Table 3 shows that over half of the community telemental health providers identified seeing patients wherever they are $(72.3 \%)$ and reaching patients who otherwise wouldn't receive care $(67.2 \%)$ as benefits of telemedicine. Over half of the providers reported barriers related to technological problems $(65.5 \%)$, whereas fewer $(29.4 \%)$ identified patient satisfaction barriers

Table 3. Perceived benefits and barriers of telemedicine in clinical practice, $N=177$.

\begin{tabular}{ccc}
\hline Perceived Benefits and Barriers of Telemedicine & $\boldsymbol{n}$ & $\mathbf{\%}$ \\
\hline Perceived benefits & & \\
Can see patients wherever they are & 128 & 72.3 \\
Can reach patients who otherwise wouldn't receive care & 119 & 67.2 \\
Can have a better work life balance & 67 & 37.9 \\
Can be at the forefront of innovative care & 57 & 32.2 \\
Can see more patients and expand practice & 50 & 28.2 \\
Can provide care the way they want, on their terms & 50 & 28.2 \\
Can cut expenses & 49 & 27.7 \\
Other & 11 & 6.2 \\
Perceived barriers & 116 & 65.5 \\
Technology problems & 66 & 37.3 \\
Security/ privacy concerns & 60 & 33.9 \\
Reimbursement issues & 55 & 31.1 \\
Legal concerns & 52 & 29.4 \\
Patient satisfaction & 5 & 2.8 \\
Competition & 9 & 5.1 \\
Other &
\end{tabular}

\subsection{Reasons for Using Telemedicine, Important Features, and Intentions for its Future Use}

Table 4 shows that over half of the providers chose to use telemedicine because it is HIPAA compliant $(88.7 \%)$ and cheaper than other solutions (56.5\%). The most important features included HIPAA compliance/security (81.4\%), free/low cost (67.2\%), and being easy for patients to use $(62.7 \%)$. Less than $50 \%$ of the providers identified a feature that should be improved to enhance the telemedicine experience. Audio/video quality and technical issues were the most commonly reported features needing improvement (identified by $48 \%$ and $37.3 \%$ of providers, respectively). Finally, over $70 \%$ of the telemental health providers stated that they intend to use telemedicine more in the future. 
Table 4. Reasons for telemedicine use, important features, and intentions for its future use, $N=177$.

\begin{tabular}{|c|c|c|}
\hline Telemedicine Features and Intentions for its Future Use & $n$ & $\%$ \\
\hline \multicolumn{3}{|l|}{ Reasons for choosing a telemedicine platform } \\
\hline HIPAA compliance & 157 & 88.7 \\
\hline Cheaper than other solutions & 100 & 56.5 \\
\hline Features that were offered & 72 & 40.7 \\
\hline Recommended by colleagues & 68 & 38.4 \\
\hline Easy to use & 64 & 36.2 \\
\hline Didn't look at other options & 29 & 16.4 \\
\hline Customer support available & 13 & 7.3 \\
\hline Organization required it & 9 & 5.1 \\
\hline \multicolumn{3}{|l|}{ Most important features of a telemedicine platform } \\
\hline HIPAA compliant and secure & 144 & 81.4 \\
\hline Free/low cost & 119 & 67.2 \\
\hline Simple and easy for patients & 111 & 62.7 \\
\hline Simple and easy for providers & 59 & 33.3 \\
\hline No downloads needed & 54 & 30.5 \\
\hline Workflow (e.g., check in, waiting room, patient queue) & 32 & 18.1 \\
\hline Extensions (e.g., payment, screenshare, group call) & 3 & 1.7 \\
\hline \multicolumn{3}{|l|}{ Telemedicine features that need to be improved } \\
\hline Improve audio/video quality & 85 & 48 \\
\hline Improve technical issues and bugs & 66 & 37.3 \\
\hline More video-call features (recording, transcription, whiteboard) & 52 & 29.4 \\
\hline Include practice management functionality (scheduling, notes) & 36 & 20.3 \\
\hline Help coordinating insurance reimbursements & 33 & 18.6 \\
\hline Help becoming more successful with telemedicine practice & 32 & 18.1 \\
\hline More reassurance regarding legal and security concerns & 29 & 16.4 \\
\hline Better integration with other health IT software I use & 20 & 11.3 \\
\hline Help me connect and network with other telemedicine providers & 18 & 10.2 \\
\hline Provide better customer support & 10 & 5.6 \\
\hline Make it easier to use & 8 & 4.5 \\
\hline \multicolumn{3}{|l|}{ Intentions to use telemedicine in the future } \\
\hline I expect to use it more & 126 & 71.2 \\
\hline I expect to use it about the same & 50 & 28.2 \\
\hline I expect to use it less & 1 & 0.6 \\
\hline
\end{tabular}

Note. Health Insurance Portability and Accountability Act (HIPAA).

\subsection{Association of Telemedicine Acceptance Features and Intentions for More Frequent Use in the Future}

Table 5 includes the results of a statistically significant multiple logistic regression model, examining the relationship between benefits of telemedicine and intentions to use telemedicine more in the future $\left(\chi^{2}=14.98, d f=7, p<0.05\right.$; Nagelkerke $\left.R^{2}=0.12\right)$. Providers who identified the following benefits of telemedicine had higher odds of intending to use it more in the future, compared with providers who did not indicate the same benefits. These benefits include: reaching patients who otherwise wouldn't receive care (odds ratio $(\mathrm{OR})=5.99, p<0.05$ ); having a better work-life balance $(\mathrm{OR}=7.13, p<0.05)$; being at the forefront of innovative care $(\mathrm{OR}=5.83, p<0.05)$; seeing more patients and expand my practice $(\mathrm{OR}=9.27, p<0.001)$; providing the care the way I want $(\mathrm{OR}=6.46, p<0.05)$; and cutting my expenses (OR $=7.40, p<0.05)$. 
Table 5. Regression for benefits of telemedicine on intentions to use telemedicine in the future.

\begin{tabular}{|c|c|c|c|}
\hline \multirow{2}{*}{ Benefits of Telemedicine } & \multirow{2}{*}{ OR } & \multicolumn{2}{|c|}{$95 \% \mathrm{CI}$} \\
\hline & & LL & UL \\
\hline \multicolumn{4}{|c|}{ Can see patients wherever they are } \\
\hline Not Selected & 1 & & \\
\hline Selected & 3.27 & 0.60 & 17.80 \\
\hline \multicolumn{4}{|c|}{ Can reach patients who otherwise wouldn't receive care } \\
\hline Not Selected & 1 & & \\
\hline Selected & $5.99 *$ & 1.20 & 29.80 \\
\hline \multicolumn{4}{|c|}{ Can have a better work-life balance } \\
\hline Not Selected & 1 & & \\
\hline Selected & $7.13 *$ & 1.51 & 33.73 \\
\hline \multicolumn{4}{|c|}{ Can be at the forefront of innovative care } \\
\hline Not Selected & 1 & & \\
\hline Selected & $5.83 *$ & 1.30 & 26.26 \\
\hline \multicolumn{4}{|c|}{ Can see more patients and expand my practice } \\
\hline Not Selected & 1 & & \\
\hline Selected & $9.27 * *$ & 1.91 & 44.98 \\
\hline \multicolumn{4}{|c|}{ Can provide care the way I want, on my terms } \\
\hline Not Selected & 1 & & \\
\hline Selected & $6.46 *$ & 1.42 & 29.42 \\
\hline \multicolumn{4}{|l|}{ Can cut my expenses } \\
\hline Not Selected & 1 & & \\
\hline Selected & $7.40 *$ & 1.54 & 35.46 \\
\hline
\end{tabular}

A subsequent analysis was conducted to examine the relationship between barriers to using telemedicine in practice and intentions to use it more in the future; however, the model resulted in poor fit $\left(\chi^{2}=7.68, d f=5, p=0.18\right.$; Nagelkerke $\left.R^{2}=0.06\right)$. We also examined the reasons why telemental health providers decided to use their current telemedicine platform and the relationship with intentions to use it more in the future, and the model approached good fit $\left(\chi^{2}=15.14, d f=8\right.$, $p=0.06$; Nagelkerke $R^{2}=0.12$ ). Providers who intended to use telemedicine more in the future chose their current platform because it was easier than other solutions $(\mathrm{OR}=3.20 ; 95 \% \mathrm{CI}=1.02-9.98$; $p=0.05)$, used and recommended by colleagues ( $\mathrm{OR}=2.59 ; 95 \% \mathrm{CI}=0.91-7.34 ; p=0.07)$, and had great customer support $(\mathrm{OR}=5.18 ; 95 \% \mathrm{CI}=0.86-31.14 ; p=0.07)$.

Table 6 includes the results of a statistically significant multiple logistic regression model, examining the relationship between telemedicine features that could be improved and intentions to use telemedicine more in the future $\left(\chi^{2}=38.55, d f=11, p<0.001\right.$; Nagelkerke $\left.R^{2}=0.28\right)$. Providers who recommended the following improvements had higher odds of intending to use telemedicine more in the future, compared to providers who did not recommend the same improvements. These include: helping coordinate health insurance reimbursements ( $\mathrm{OR}=4.29, p<0.05)$; assisting in becoming more successful in their telemedicine practice $(\mathrm{OR}=13.17, p<0.05)$; and integrating the platform with other health IT software (OR $=5.45, p<0.05)$. We also examined the relationship between important telemedicine features and intentions to use telemedicine more in the future, but the model had poor fit $\left(\chi^{2}=5.81, d f=7, p=0.56\right.$; Nagelkerke $\left.R^{2}=0.05\right)$ and was not pursued further. 
Table 6. Regression of telemedicine features that need improvement on intentions for its future use.

\begin{tabular}{|c|c|c|c|}
\hline \multirow{2}{*}{ Features Needing Improvement } & \multirow{2}{*}{ OR } & \multicolumn{2}{|c|}{$95 \%$ CI } \\
\hline & & LL & UL \\
\hline \multicolumn{4}{|l|}{ Improve audio/video quality } \\
\hline Not Selected & 1 & & \\
\hline Selected & 0.67 & 0.30 & 1.48 \\
\hline \multicolumn{4}{|l|}{ Improve technical issues and bugs } \\
\hline Not Selected & 1 & & \\
\hline Selected & 0.60 & 0.27 & 1.35 \\
\hline \multicolumn{4}{|c|}{ More video-call features (recording, transcription, whiteboard) } \\
\hline Not Selected & 1 & & \\
\hline Selected & 1.75 & 0.75 & 4.09 \\
\hline \multicolumn{4}{|c|}{ Include practice management functionality (scheduling, notes) } \\
\hline Not Selected & 1 & & \\
\hline Selected & 0.81 & 0.27 & 2.37 \\
\hline \multicolumn{4}{|c|}{ Help coordinating insurance reimbursements } \\
\hline Not Selected & 1 & & \\
\hline Selected & $4.29 *$ & 1.16 & 15.89 \\
\hline \multicolumn{4}{|c|}{ Help becoming more successful with telemedicine practice } \\
\hline Not Selected & 1 & & \\
\hline Selected & 13.17 * & 1.57 & 110.82 \\
\hline \multicolumn{4}{|c|}{ More reassurance regarding legal and security concerns } \\
\hline Not Selected & 1 & & \\
\hline Selected & 0.72 & 0.25 & 2.07 \\
\hline \multicolumn{4}{|c|}{ Better integration with other health IT software I use } \\
\hline Not Selected & 1 & & \\
\hline Selected & $5.45 *$ & 1.12 & 26.39 \\
\hline \multicolumn{4}{|c|}{ Help me connect and network with other telemedicine providers } \\
\hline Not Selected & 1 & & \\
\hline Selected & 1.75 & 0.18 & 16.69 \\
\hline \multicolumn{4}{|l|}{ Provide better customer support } \\
\hline Not Selected & 1 & & \\
\hline Selected & 0.96 & 0.19 & 4.80 \\
\hline \multicolumn{4}{|l|}{ Make it easier to use } \\
\hline Not Selected & 1 & & \\
\hline Selected & 6.21 & 0.68 & 56.41 \\
\hline
\end{tabular}

\section{Discussion}

The purpose of this report was to describe the characteristics of telemental health providers and telemedicine features that contribute to their intentions to use it more often in clinical practice. Despite being registered users of a telemedicine platform, the providers in this report did not frequently use the platform for telemental health visits. Nearly $75 \%$ of the providers used telemedicine to deliver telemental health care $<25 \%$ of the time they interacted with patients. Providers held positive beliefs about the capacity of telemedicine to increase patient access to care, yet they also reported perceived barriers about patient security and technological challenges. Most providers reported that HIPAA compliance was a strong motivator and important feature of their current telemedicine platform. However, positive beliefs about telemedicine and the need for more specialized support were strong predictors of intentions to more frequently use telemedicine in practice. In addition to providing a baseline assessment for the acceptability of telemedicine pre-COVID-19, this report provides formative data to inform interventions to increase the uptake and frequent use of telemental health services. 


\subsection{Principal Findings}

The majority of community telemental health providers surveyed in this report were female, white, non-Hispanic, licensed mental health counselors and social workers employed within individual practice settings or small clinics. These characteristics are similar to those observed in the overall workforce in the US [36,37]. Half of the providers reported that they billed health insurance companies for telemental health visits, the majority of whom were master's-level providers in individual practice. This was much higher than in the study by Gershkovich et al. [24], who found that 15.8\% of providers reported billing insurance for telemental health visits. One reason for increases in insurance billing may be a result of updates in telehealth regulations and policies [38]. Even with the recent policy improvements, however, barriers still exist that prevent patients who do not live in rural areas or are not covered by Medicare to access affordable telehealth services [38,39]. Evidence to demonstrate the clinical and patient-reported benefits of telemental health care among rural and non-rural patients will be important for addressing this regulatory limitation.

A commonly reported benefit of telemedicine included increasing patient access to care and its most important feature was HIPAA compliance, followed by being low-cost and easy-to-use. Although there are regulatory standards to ensure HIPAA-compliance in data sharing and communication via telemedicine [40], about $70 \%$ of providers expressed concerns about the impact of technological problems and 40\% indicated security/privacy concerns related to telemedicine. Li [41] found that the degree to which a person feels confident in their ability to manage their online personal security and privacy will influence their skills to effectively use technology to achieve their health-related goals. Therefore, greater attention must be paid to enhancing community telemental health providers' skills to effectively use telemedicine platforms. Enhancing confidence that patients can use the technology to effectively engage with them during telemental health visits will also be important. To achieve this goal, providers must maintain transparency and fidelity when interacting with patients during these visits [42]. Telemedicine platforms may also serve a role in providing reassurance to both patients and providers by indicating whether or not its features are evidence-based and had undergone user-centered design testing.

Consistent with technology adoption models [30], telemental health providers selected their current telemedicine platform if it included features that were important to their practice. Interestingly, these features did not reinforce providers' intentions to use telemental health services more often in the future. Instead, the perceived benefits of using telemedicine and the desired need to improve the workflow of telemental health services were associated with intentions for its more frequent use in the future. These workflow improvements included needing assistance to coordinate health insurance reimbursements, facilitate a successful telemedicine practice, and integrate the telemedicine program with existing health IT solutions. This finding reflects a socio-ecological perspective towards telemedicine adoption [43], supporting that its acceptance includes providers' beliefs about its usefulness and ease-of-use, as well as the capacity of their healthcare organization to facilitate its successful implementation in practice.

\subsection{Limitations}

This report includes a secondary analysis of de-identified marketing data from a commercial telemedicine company, meaning we had little control over the sampling and recruitment processes. First, data were collected using a purposive sampling approach. Because there was no sampling frame, potentially knowledgeable and appropriate individuals may have been excluded. We were unable to assess any bias between those who responded to the survey and those who did not respond, because we did not draw from an already constructed sampling frame. Although this raises concerns about the external validity of the results, we note above that the socio-demographic characteristics of our sample is representative of the workforce in the US. Findings should be explored and confirmed among telemental health providers who broadly use telehealth programs, including other telemedicine platforms. A second limitation that contributes to the generalizability of results is the low survey 
response rate. Although this rate is consistent with the average response rates of other web-based surveys [44], our absent sampling frame and approach to recruitment may begin to explain the low response rate. A randomized sample of telemental health providers would be ideal for future research on this topic, specifically one that applies stratification procedures to ensure that various types of providers (i.e., social workers, psychologists) and their place of practice (i.e., small clinics, individual clinics) are represented. In regard to recruitment, more efforts could have been made to promote responses such as reminder emails, phone calls and texts. The confidence intervals in this study's multiple logistic regression analyses lacked precision. However, VIFs for each independent variable across all regression analyses were less than 5.0, which is less than the recommended cut-off of 10.0 to signal serious multicollinearity between variables within a given model [45]. To better understand the relationship between telemedicine features and intentions to use the technology more in the future, future research with a larger sample of providers who affirm the desire or need for particular telemedicine features (e.g., help becoming more successful with their telemedicine practice) is needed.

\subsection{Practical and Theoretical Implications}

Although all providers who completed the survey were registered telemedicine users, the frequency with which they used the technology in practice was considerably low. Providers who indicated an interest in using telemedicine more often in the future were drawn to the patient-centric benefits of telemedicine, and desired more support in making telemedicine a central aspect of their clinical practice. The development and adaptation of telemedicine features to better support telemental health providers' workflow may take a significant amount of time and resources. To begin making a low-cost impact on increasing how frequently mental health providers use telemedicine services, healthcare companies and organizations may consider testing message-based interventions that reinforce the perceived benefits and efficacy of using telemedicine. For example, messages could reinforce that telemental health visits increase patient access to high-quality care and highlight the value of a HIPAA-compliant telemedicine platform, if applicable. Drawing from technology adoption models and behavior change theory, such as the Transtheoretical Model of Behavior Change [46], may be especially useful in tailoring messages to those in the contemplation and preparation stages of increasing the frequency in which they use telemedicine in clinical practice.

This study also has important theoretical implications that should be considered for future research and practice. The TAM may be a worthwhile framework for understanding the initial uptake of telemedicine [31], but the features of other technology adoption models are useful for understanding how to increase its use over time. According to a systematic review by Harst et al. [31], the Unified Theory of Acceptance and Use of Technology (UTAUT) includes facilitating conditions as a central feature of telemedicine use. Facilitating conditions are infrastructural features that support the utilization of telemedicine in healthcare systems and organizations [31]. In a recent study conducted in tele-dermatology [47], researchers found that healthcare providers' perceptions of the infrastructural capacity of their healthcare systems (i.e., facilitators) was the strongest predictor for their intention to use the technology in the future, more so than the perceived usefulness of telemedicine and its ease-of-use. This is consistent with the results of the current study, which found that the perceived importance of various telemedicine features did not influence intentions to use the technology. Rather, telemental health providers' desired needs for support, related to health insurance reimbursement, successful telemedicine practice management and health IT integration, predicted this future use. Results support the recommended modifications of technology acceptance models to consider system-level facilitators of technology use [43,47]. Results also provide insight about which system factors are most impactful on telemental health providers' intentions to use telemedicine in the future.

Intervening on system-level factors related to telemedicine acceptance requires a strategic approach. One approach includes the integration of telemedicine with health IT programs, including 
electronic health records (EHRs), which have become integral to coordinating care across healthcare delivery systems. EHR systems increase the transparency and efficiency of healthcare coordination by streamlining how patient and insurance data are accessed, entered, and monitored by providers, among other impactful capabilities [48,49]. Healthcare providers can become advocates in this area by understanding what type of integration is best and feasible for their practice. As such, further research is needed to understand disparities in its integration across geographic regions where healthcare resources are sparse, as well as the personal and professional demographics (i.e., medical specialties and sub-specialties) of telemental health providers.

Due to the recent acceleration of telemedicine due to COVID-19 pandemic, regulatory and financial barriers to telemedicine reimbursement have now been alleviated. For example, on 13 March 2020, the Trump Administration announced an emergency declaration under the Stafford Act and the National Emergencies Act, which led to the Center for Medicare \& Medicaid Services (CMS) expanding telehealth benefits [50]. Many private insurance companies have also expanded their policy coverage on telehealth [51]. In addition, the Office for Civil Rights (OCR) enforced discretion for telehealth remote services during the COVID-19 public health emergency, resulting in ease of HIPAA restrictions with hope of good faith provision [52]. While the OCR's enforcement discretion does relax restrictions on telehealth and may increase concern on level of security, it is only temporary for the duration of the public health emergency. This report provides a baseline assessment for telemental health care providers' characteristics and acceptability of telemedicine in practice. Future research is needed to examine how the characteristics and use of telemedicine has changed in response to the COVID-19 pandemic, and whether or not any changes are sustained over a significant period of time.

\section{Conclusions}

This study explores the characteristics of community telemental health providers who use telemedicine, and how telemedicine features are associated with intentions to use the technology more often in the future. Although providers believed that telemental health increases patient access to care, they also had concerns about patient security, safety, and technology challenges. Findings demonstrate that positive beliefs about telemedicine are significant predictors for its frequent uptake in the future. Given that mental health providers want to use telemedicine more frequently in their practice, there is a significant need to identify methods to help them achieve this goal. In this study, providers indicated that this could be achieved by receiving assistance to coordinate health insurance reimbursements, manage a successful telemedicine practice, and facilitate a better integration of telemedicine into other health IT solutions. Research is needed to develop interventions that leverage these useful determinants of telemental health acceptability to increase providers' weekly use of telemedicine. Telemedicine has the potential to revolutionize mental health care delivery; therefore, optimizing its routine use among its gatekeepers is a priority.

Author Contributions: Conceptualization, B.M.W., D.T. and B.E.B.; methodology, B.M.W., D.T. and B.E.B.; formal analysis, S.R.P. and B.E.B.; investigation, B.M.W. and D.T.; resources, B.M.W., D.T.; data curation, D.T. and B.E.B.; writing-original draft preparation, B.E.B., J.F.B. and S.R.P.; writing-review and editing, B.E.B., J.F.B., B.M.W., D.T. and S.R.P.; All authors have read and agreed to the published version of the manuscript.

Funding: Brian E. Bunnell was funded by the National Institute of Mental Health, grant number MH118482.

Conflicts of Interest: Brandon M. Welch and Dylan Turner are shareholders of doxy.me, LLC. Brian E. Bunnell, Samantha R. Paige and Janelle F. Barrera are employed by doxy.me, LLC. 


\section{References}

1. Khairat, S.; Liu, S.; Zaman, T.; Edson, B.; Gianforcaro, R. Factors determining patients' choice between mobile health and telemedicine: Predictive analytics assessment. JMIR MHealth uHealth 2019, 7, e13772. [CrossRef] [PubMed]

2. Weinstein, R.S.; Lopez, A.M.; Joseph, B.A.; Erps, K.A.; Holcomb, M.; Barker, G.P.; Krupinski, E.A. Telemedicine, telehealth, and mobile health applications that work: Opportunities and barriers. Am. J. Med. 2014, 127, 183-187. [CrossRef] [PubMed]

3. CDC Coronavirus Disease 2019 (COVID-19). Available online: https://www.cdc.gov/coronavirus/2019-ncov/ hcp/guidance-hcf.html (accessed on 14 May 2020).

4. Portnoy, J.; Waller, M.; Elliott, T. Telemedicine in the era of COVID-19. J. Allergy Clin. Immunol. Pract. 2020, 8 , 1489-1491. [CrossRef]

5. Sable, C.A.; Cummings, S.D.; Pearson, G.D.; Schratz, L.M.; Cross, R.C.; Quivers, E.S.; Rudra, H.; Martin, G.R. Impact of telemedicine on the practice of pediatric cardiology in community hospitals. Pediatrics 2002, 109 , e3. [CrossRef] [PubMed]

6. Misra, U.K.; Kalita, J.; Mishra, S.K.; Yadav, R.K. Telemedicine in neurology: Underutilized potential. Neurol. India 2005, 53, 27. [CrossRef]

7. Darkins, A.; Ryan, P.; Kobb, R.; Foster, L.; Edmonson, E.; Wakefield, B.; Lancaster, A.E. Care coordination/home telehealth: The systematic implementation of health informatics, home telehealth, and disease management to support the care of veteran patients with chronic conditions. Telemed. e-Health 2008, 14, 1118-1126. [CrossRef]

8. Lee, C.J.; Park, S. The role of home blood pressure telemonitoring for blood pressure control. Pulse 2016, 4, 78-84. [CrossRef]

9. Doolittle, G.C.; Spaulding, A.O. Providing access to oncology care for rural patients via telemedicine. J. Oncol. Pract. 2006, 2, 228-230. [CrossRef]

10. Hilty, D.M.; Ferrer, D.C.; Parish, M.B.; Johnston, B.; Callahan, E.J.; Yellowlees, P.M. The effectiveness of telemental health: A 2013 review. Telemed. e-Health 2013, 19, 444-454. [CrossRef]

11. Flodgren, G.; Rachas, A.; Farmer, A.J.; Inzitari, M.; Shepperd, S. Interactive telemedicine: Effects on professional practice and health care outcomes. Cochrane Database Syst. Rev. 2015, CD002098. [CrossRef]

12. Langarizadeh, M.; Tabatabaei, M.S.; Tavakol, K.; Naghipour, M.; Rostami, A.; Moghbeli, F. Telemental health care, an effective alternative to conventional mental care: A systematic review. Acta Inform. Med. 2017, 25, 240-246. [CrossRef] [PubMed]

13. Adams, S.M.; Rice, M.J.; Jones, S.L.; Herzog, E.; Mackenzie, L.J.; Oleck, L.G. Telemental health: Standards, reimbursement, and interstate practice. J. Am. Psychiatr. Nurses Assoc. 2018, 24, 295-305. [CrossRef] [PubMed]

14. Baker, L.C.; Johnson, S.J.; Macaulay, D.; Birnbaum, H. Integrated telehealth and care management program for Medicare beneficiaries with chronic disease linked to savings. Health Aff. 2011, 30, 1689-1697. [CrossRef] [PubMed]

15. Rojas, S.V.; Gagnon, M.-P. A systematic review of the key indicators for assessing telehomecare cost-effectiveness. Telemed. J. e-Health 2008, 14, 896-904. [CrossRef] [PubMed]

16. Thaker, D.A.; Monypenny, R.; Olver, I.; Sabesan, S. Cost savings from a telemedicine model of care in Northern Queensland, Australia. Med. J. Aust. 2013, 199, 414-417. [CrossRef]

17. Wootton, R.; Bahaadinbeigy, K.; Hailey, D. Estimating travel reduction associated with the use of telemedicine by patients and healthcare professionals: Proposal for quantitative synthesis in a systematic review. BMC Health Serv. Res. 2011, 11, 185. [CrossRef]

18. Bashshur, R.L.; Shannon, G.W.; Bashshur, N.; Yellowlees, P.M. The empirical evidence for telemedicine interventions in mental disorders. Telemed. J. e-Health 2016, 22, 87-113. [CrossRef]

19. Choi, S.; Wilcock, A.D.; Busch, A.B.; Huskamp, H.A.; Uscher-Pines, L.; Shi, Z.; Mehrotra, A. Association of characteristics of psychiatrists with use of telemental health visits in the Medicare population. JAMA Psychiatry 2019, 76, 654-657. [CrossRef]

20. Shi, Z.; Huskamp, H.A.; Souza, J.; Busch, A.B.; Uscher-Pines, L.; Mehrotra, A. Characteristics of organizations that provide telemental health. Healthc. Transform. 2019, 11-13. [CrossRef]

21. Mehrotra, A.; Jena, A.B.; Busch, A.B.; Souza, J.; Uscher-Pines, L.; Landon, B.E. Utilization of telemedicine among rural Medicare beneficiaries. JAMA 2016, 315, 2015-2016. [CrossRef] 
22. Mehrotra, A.; Huskamp, H.A.; Souza, J.; Uscher-Pines, L.; Rose, S.; Landon, B.E.; Jena, A.B.; Busch, A.B. Rapid growth in mental health telemedicine use among rural Medicare beneficiaries, wide variation across states. Health Aff. 2017, 36, 909-917. [CrossRef] [PubMed]

23. Simms, D.C.; Gibson, K.; O’Donnell, S. To use or not to use: Clinicians' perceptions of telemental health. Can. Psychol. 2011, 52, 41-51. [CrossRef]

24. Gershkovich, M.; Herbert, J.D.; Glassman, L.H.; Ibrahim, A.; Forman, E.M.; Kaye, J.L. Clinicians' attitudes and experiences regarding telemental health services. Behav. Ther. 2016, 39, 14-20.

25. Douglas, M.D.; Xu, J.; Heggs, A.; Wrenn, G.; Mack, D.H.; Rust, G. Assessing telemedicine utilization by using Medicaid claims data. Psychiatr. Serv. 2017, 68, 173-178. [CrossRef] [PubMed]

26. Barnett, M.L.; Ray, K.N.; Souza, J.; Mehrotra, A. Trends in telemedicine use in a large commercially insured population, 2005-2017. JAMA 2018, 320, 2147-2149. [CrossRef]

27. Whitten, P.S.; Mackert, M.S. Addressing telehealth's foremost barrier: Provider as initial gatekeeper. Int. J. Technol. Assess. Health Care 2005, 21, 517-521. [CrossRef]

28. Jameson, J.P.; Farmer, M.S.; Head, K.J.; Fortney, J.; Teal, C.R. VA community mental health service providers' utilization of and attitudes toward telemental health care: The gatekeeper's perspective. J. Rural Health 2011, 27, 425-432. [CrossRef]

29. Cowan, K.E.; McKean, A.J.; Gentry, M.T.; Hilty, D.M. Barriers to use of telepsychiatry: Clinicians as gatekeepers. Mayo Clin. Proc. 2019, 94, 2510-2523. [CrossRef]

30. Davis, F.D. Perceived usefulness, perceived ease of use, and user acceptance of information technology. Miss Q. 1989, 13, 319-340. [CrossRef]

31. Harst, L.; Lantzsch, H.; Scheibe, M. Theories predicting end-user acceptance of telemedicine use: Systematic review. J. Med. Internet Res. 2019, 21, e13117. [CrossRef]

32. FAQ's on Telehealth and HIPAA during the COVID-19 Nationwide Public Health Emergency. Available online: https://www.hhs.gov/sites/default/files/telehealth-faqs-508.pdf (accessed on 14 May 2020).

33. How to Maintain Momentum on Telehealth After COVID-19 Crisis Ends. Available online: https://www.amaassn.org/practice-management/digital/how-maintain-momentum-telehealth-after-covid-19-crisis-ends (accessed on 27 September 2020).

34. Welch, B.M.; Marshall, E.; Qanungo, S.; Aziz, A.; Laken, M.; Lenert, L.; Obeid, J. Teleconsent: A novel approach to obtain informed consent for research. Contemp. Clin. Trials Commun. 2016, 3, 74-79. [CrossRef] [PubMed]

35. Bunnell, B.E.; Sprague, G.; Qanungo, S.; Nichols, M.; Magruder, K.; Lauzon, S.; Obeid, J.S.; Lenert, L.A.; Welch, B.M. An exploration of useful telemedicine-based resources for clinical research. Telemed. J. e-Health 2020, 23, 51-65. [CrossRef] [PubMed]

36. Salsberg, E.; Quigley, L.; Mehfoud, N.; Acquaviva, K.D.; Wyche, K.; Silwa, S. Profile of the Social Work Workforce; Council on Social Work Education and National Workforce Initiative Steering Committee: Alexandria, VA, USA; George Washington University Health Workforce Institute and School of Nursing: Washington, DC, USA, 2017.

37. Lin, L.; Stamm, K.; Christidis, P. Demographics of the US Psychology Workforce: Findings from the 2007-16 American Community Survey; American Psychological Association Center for Workforce Studies: Washington, DC, USA, 2018.

38. Center for Disease Control and Prevention Public Health and Promoting Interoperability Programs. Available online: https://www.cdc.gov/ehrmeaningfuluse/introduction.html (accessed on 15 April 2020).

39. CMS Finalizes Policies to Bring Innovative Telehealth Benefit to Medicare Advantage. Available online: https://www.cms.gov/newsroom/press-releases/cms-finalizes-policies-bring-innovativetelehealth-benefit-medicare-advantage (accessed on 20 April 2020).

40. Omnibus HIPAA Rulemaking. Available online: https://www.hhs.gov/hipaa/for-professionals/privacy/lawsregulations/combined-regulation-text/omnibus-hipaa-rulemaking/index.html (accessed on 13 April 2020).

41. $\mathrm{Li}, \mathrm{X}$. Understanding eHealth literacy from a privacy perspective: eHealth literacy and digital privacy skills in American disadvantaged communities. Am. Behav. Sci. 2018, 62, 1431-1449. [CrossRef]

42. Chaet, D.; Clearfield, R.; Sabin, J.E.; Skimming, K. Council on ethical and judicial affairs American medical association ethical practice in telehealth and telemedicine. J. Gen. Intern. Med. 2017, 32, 1136-1140. [CrossRef] [PubMed]

43. Apho, B.; Labonte, R.; Bourgeault, I.L.; Niang, M.N. The individual and contextual determinants of the use of telemedicine: A descriptive study of the perceptions of Senegal's physicians and telemedicine projects managers. PLoS ONE 2017, 12, e0181070.

44. Cook, C.; Heath, F.; Thompson, R.L. A meta-analysis of response rates in web- or internet-based surveys. Educ. Psychol. Meas. 2000, 60, 821-836. [CrossRef] 
45. Cohen, J.; Cohen, P.; West, S.G.; Aiken, L.S. Outliers and multicollinearity: Diagnosing and solving regression problems II. In Applied Multiple Regression/Correlation Analysis for the Behavioral Science, 3rd ed.; Routledge-Taylor and Francis Group: New York, NY, USA, 2003; pp. 390-430.

46. Prochaska, J.O.; DiClemente, C.C. Stages and processes of self-change of smoking: Toward an integrative model of change. J. Consult. Clin. Psychol. 1983, 51, 390-395. [CrossRef]

47. Gagnon, M.P.; Orruno, E.; Asua, J.; Abdelijelil, A.B.; Emparanza, J. Using a modified technology acceptance model to evaluate health professionals' adoption of a new telemonitoring system. Telemed. e-Health 2012, 18, 55-59. [CrossRef]

48. What Are the Advantages of Electronic Health Records? Available online: https://www.healthit.gov/faq/ what-are-advantages-electronic-health-records (accessed on 29 October 2020).

49. Menachemi, N.; Collum, T.H. Benefits and drawbacks of electronic health record systems. Risk Manag. Healthc. Policy 2011, 4, 47-55. [CrossRef]

50. Medicare Telemedicine Health Care Provider Fact Sheet. Available online: https://www.cms.gov/newsroom/ fact-sheets/medicare-telemedicine-health-care-provider-fact-sheet (accessed on 9 April 2020).

51. Health Insurance Providers Respond to Coronavirus (COVID-19). Available online: https://www.ahip.org/ health-insurance-providers-respond-to-coronavirus-covid-19/ (accessed on 9 April 2020).

52. Office for Civil Rights Notification of Enforcement Discretion for Telehealth. Available online: https://www.hhs.gov/hipaa/for-professionals/special-topics/emergency-preparedness/notificationenforcement-discretion-telehealth/index.html (accessed on 10 April 2020).

Publisher's Note: MDPI stays neutral with regard to jurisdictional claims in published maps and institutional affiliations.

(C) 2020 by the authors. Licensee MDPI, Basel, Switzerland. This article is an open access article distributed under the terms and conditions of the Creative Commons Attribution (CC BY) license (http://creativecommons.org/licenses/by/4.0/). 